\title{
Changes in intraocular pressure, horizontal pupil diameter, and tear production during the use of topical $1 \%$ cyclopentolate in cats and rabbits
}

\author{
Liga Kovalcuka* and Madara Nikolajenko \\ Faculty of Veterinary Medicine, Clinical Institute,Latvia University of Life Sciences and Technologies, Jelgava, \\ Latvia
}

\begin{abstract}
Background: Cyclopentolate is not commonly used as mydriatic drug in veterinary medicine because of limited data on the local and systemic effects in animals.

Aim: To determine the effects of topical $1 \%$ cyclopentolate hydrochloride on intraocular pressure (IOP), horizontal pupil diameter (HPD) and tear production in the cat and rabbit's eye during the first hour and up to 36 hours after treatment.

Methods: One drop of $1 \%$ cyclopentolate hydrochloride was used in the left eye in 10 clinically and ophthalmologically healthy domestic cats and 10 rabbits. IOP and HPD were recorded every 5 minutes during the first hour, then every 2 hours during the following 12-hour period, and at 24 and 36 hours after application. Schirmer tear test (STT) was measured at 30 and 60 minute after treatment, then in same time points as IOP and HPD. Rebound tonometer (TonoVet ${ }^{\mathbb{R}}$ ) was used to assess IOP, Jameson calliper to measure HPD and STT to determine the tear production.

Results: $1 \%$ cyclopentolate increased IOP in cats, reaching a maximum $(28.1 \pm 5.4 \mathrm{mmHg})$ at $T_{50}$ and in rabbits at $\mathrm{T}_{25}(16.7 \pm 1.3 \mathrm{mmHg})$. Maximal mydriasis in cats was observed at $T_{40}$ and lasted 24-36 hours, but in rabbits at $T_{25}$. and returned to pre-treatment values at $T_{10 \mathrm{~h}}-T_{12 \mathrm{~h}}$. In cats, STT decreased in both eyes 30 minutes after treatment and remained lower throughout the 36-hour period. In rabbits, STT decreased in the treated eye 30 minutes after treatment, but all following STT measurements returned to normal pre-treatment levels.

Conclusion: Study showed novel data about the effects of $1 \%$ cyclopentolate to IOP, HPD, STT in cats and rabbits. Cyclopentolate in cats caused mydriasis 20-40 minutes after the treatment by increasing IOP, at the same time, pupil diameter reached pre-treatment values 24-36 hours after treatment. In rabbit's mydriasis occurred faster, 10-25 minutes after treatment without significant IOP increase and mydriasis lasted 10-12 hours. Significant STT decrease was recorded in cats, but more likely were connected to stress factors. This drug could be considered as a therapeutical alternative in rabbit more than in cats.
\end{abstract}

Keywords: Cyclopentolate, Horizontal pupil diameter, Intraocular pressure, Tear production.

\section{Introduction}

In ophthalmology, mydriatics, such as tropicamide hydrochloride, atropine sulphate and cyclopentolate hydrochloride, are used for pupil dilation for the examination of the posterior segment of the eye. Tropicamide is also used as a therapeutic agent for a treatment of uveitis and atropine for relieving ciliary spasm through cycloplegia, thus, preventing formation of the synechia through mydriasis (Smith and Reynard, 1992; Ward, 1998). Phenylephrine is used to localize the site of sympathetic denervation in Horner's syndrome, producing mydriasis as a part of sympathomimetic action (Smith and Reynard, 1992; Ward, 1998). Cyclopentolate hydrochloride is a parasympatolitic agent the same as tropicamide and atropine with anti-muscarinic activity and causes pupillary dilatation followed by ciliary muscle paralysis (Smith and Reynard, 1992; Ward, 1998). Cyclopentolate hydrochloride was introduced into clinical practice in 1951 and today are mainly used in human medicine, regularly in Pediatric and Adult Ophthalmology to dilate pupils during eye examination (Hug and Olitsky, 2007). Cyclopentolate hydrochloride maximum mydriatic effect is reported in 20-30 minutes in the lightly pigmented irides and in 30-60 minutes in people with heavily pigmented irides (Harris, 1968). During this dilation, an increase in intraocular pressure (IOP) has been noticed in narrow-angle and normal angle human patients (Harris and Galin, 1969; Velasco et al., 1998).

Cyclopentolate is not commonly used in veterinary medicine, and there is a lack of data about the effects of cyclopentolate on intraocular pressure (IOP), horizontal pupil diameter (HPD), and other values like Schirmer tear test (STT). The effects of topical $1 \%$ tropicamide, $1 \%$ homatropine, $1 \%$ cyclopentolate, $1 \%$ atropine, and $0.25 \%$ hyoscine mydriatic effect (vertical and HPD) have been investigated in Angora goats (Whelan et al., 2011). The research showed a good mydriatic effect with $1 \%$ cyclopentolate within 15 minutes after the

*Corresponding Author: Liga Kovalcuka. Faculty of Veterinary Medicine, Clinical Institute, Latvia University of Life Sciences and Technologies, Jelgava, Latvia. Email: kovalcuka@gmail.com 
treatment, reaching maximum horizontal mydriasis in 1 hour. However, the authors specified that it took too long to reach maximum dilation for routine mydriasis. Costa et al. (2016) reported on the effects of $1 \%$ cyclopentolate on tear production, pupil size, and IOP in healthy beagles up to 96 hour post-application and cyclopentolate had been considered as a therapeutic alternative in cases where effects on tear production and IOP are undesirable. So far, the only publication on the effects of topical $1 \%$ cyclopentolate in cats demonstrated a significant IOP increase at one, 1.5 and 2 hours after the treatment (Stadtbäumer et al., 2006).

There are very limited data on the effects of cyclopentolate in animals and in the author's knowledge there are no data concerning the effects of cyclopentolate in rabbits; therefore, the purpose of this study was to determine the effects of topical $1 \%$ cyclopentolate hydrochloride on the IOP, HPD, and STT in the cat and rabbit eye during the first hour and up to 36 hours after the treatment.

\section{Materials and Methods}

\section{Data}

All animals examined were privately-owned outpatients at the Clinical Institute of the Faculty of Veterinary Medicine at the Latvia University of Life Sciences and Technologies.

All animals included in this study were given a complete physical and ophthalmological examine by the same person to ensure that they were systemically and ophthalmologically healthy. The clinical examination included signalment (animal breed, age, and sex) general appearance, vital signs (body weight, temperature, heart/pulse rate, respiratory rate), and a physical examination (systems approach). The ocular examination included direct ophthalmoscopy (Keeler Practitioner, Windsor, UK), monocular ophthalmoscopy with the PanOptic ophthalmoscope (Welch Alynn, Romford, UK) and slit-lamp biomicroscopy (Kowa SL15, Nagoya, Aichi, Japan). Tonometry with the Tonovet tonometer (TonoVet $\AA$, Tiolat Ltd. Finland) was part of the initial examination.

The cat group contained 10 randomly assigned cats and the rabbit group 10 randomly assigned rabbits (Table 1). Cats and rabbits received one drop of $1 \%$ cyclopentolate hydrochloride (Alcon-Couvreur, Belgium) in the left eye, the right eye was used as a control.

In both groups, the first IOP, HPD, and STT I measurements were taken before treatment $\left(T_{0}\right)$. After treatment, IOP and HPD were recorded every 5 minutes in both eyes during the first hour $\left(T_{5} ; T_{10} ; \ldots T_{60}\right)$, then every 2 hours during the following 12-hour period, and then at $24\left(T_{24 \mathrm{~h}}\right)$ and $36\left(T_{36 \mathrm{~h}}\right)$ hours after application. STT was measured at $30\left(T_{30}\right)$ and $60\left(T_{60}\right)$ min after treatment, then every 2 hours during the 12-hour period, and then at $24\left(T_{24 \mathrm{~h}}\right)$ and $36\left(T_{36 \mathrm{~h}}\right)$ hours after application. During all measurements, the animals were handled gently to avoid any tension on the animal's neck which might influence IOP (Pauli et al., 2006).

All tonometric measurements were performed by the same person employing rebound tonometry with the Tonovet tonometer (TonoVet $\AA$, Tiolat Ltd. Finland), in the $(d)$ calibration setting, with automatic calibration provided by the device. Each measurement recorded was the automatically generated average after five successive readings. The use of topical anaesthesia is not required for this tonometer.

The HPD was measured with Jameson calipers under fixed light conditions every 5 minutes as described above. All measurements were done at the approximately the same time of Day (9.00-11.00 am) to minimize the effects of changing light conditions at different times of day on the IOP and the HPD (Gelatt et al., 1981; Giannetto et al., 2009).

STT was measured with the standardized sterile STT-I strips (Eickemeyer, Tuttlingen, Germany). The tip of the strip was inserted in the lower lateral eyelid margin in the conjunctival fornix for 60 seconds. After the removal of the test strip, the length of the wet section was immediately measured in millimetres.

\section{Statistical method}

Statistical analysis of the data was performed using statistical software programs SPSS and Microsoft Excel. Normality was tested using Shapiro-Wilk test. To determine the effect of topical $1 \%$ cyclopentolate,

Table 1. Animal signalment.

\begin{tabular}{|c|c|c|c|}
\hline & Age & Sex & Breed \\
\hline \multirow{10}{*}{$\begin{array}{l}\text { Group } 1 \\
\text { (cats) }\end{array}$} & 2 years & Male neutered & Mixed \\
\hline & 1.5 years & Male neutered & Mixed \\
\hline & 10 months & Female entire & Mixed \\
\hline & 14 years & Female neutered & Persian mixed \\
\hline & 12 years & Male neutered & Persian mixed \\
\hline & 2.5 years & Female neutered & Mixed \\
\hline & 2.5 years & Female neutered & Mixed \\
\hline & 3 years & Female neutered & Mixed \\
\hline & 3.5 years & Female neutered & Mixed \\
\hline & 2 years & Male neutered & Mixed \\
\hline \multirow{10}{*}{$\begin{array}{l}\text { Group } 2 \\
\text { (rabbits) }\end{array}$} & 1 year & Female entire & Mixed \\
\hline & 2 years & Female entire & Mixed \\
\hline & 2 years & Female entire & Mixed \\
\hline & 3 years & Female entire & Mixed \\
\hline & 4 years & Female entire & Mixed \\
\hline & 2 years & Female entire & Mixed \\
\hline & 2 years & Female entire & Mixed \\
\hline & 2 years & Female entire & Mixed \\
\hline & 3 years & Female entire & Mixed \\
\hline & 4 years & Female entire & Mixed \\
\hline
\end{tabular}


the arithmetic mean values $(X)$ and standard deviation (SD) of the IOP, HPD, and the STT was calculated for each eye separately. Changes in the IOP, HPD, and STT between eyes and over time were evaluated using a paired two-sample repeated measures T-test. $p$ values less than 0.05 were considered to be statistically significant.

\section{Ethical approval}

This study was approved by the Committee for Animal Protection and Ethical use. In all cases, informed consent was obtained from the pet owners for the study.

\section{Results}

During the study, no signs of ocular irritation or pain were detected in any of the animals examined at any time point. Effects of 1\% cyclopentolate on IOP in cats and rabbits Initial pre-treatment IOP in cats and rabbits are shown in Table 2. Mean IOP values before topical cyclopentolate application between right and left eye were not significantly different $(p=0.879)$.

The effects of $1 \%$ cyclopentolate during the first treatment hour are shown in Figure 1. In the cats, IOP in cats increased at $T_{5}$, the first post-treatment measurement in the treated eye. A statistically significant increase was reached at $T_{20}(24.9 \pm 4.5 \mathrm{mmHg})$ and at $T_{50}$ time point IOP had increased from the pre-treatment value for a mean of $7 \pm 4.0 \mathrm{mmHg}$ to a maximum $28.1 \pm 5.4$ $\mathrm{mmHg}(p=0.004)$ (Table 2). From this time, forward IOP slowly decreased but still was significantly higher than pre-treatment values until 2 hours after treatment, showing values from 19.9 to $28.1 \mathrm{mmHg}$. Only 4 hours after treatment, IOP returned to $\mathrm{T}_{0}$ values $(p>0.05)$. The increase in IOP in the treated eye compared to the untreated eye was statistically significant at the $T_{40}, T_{45}$, $T_{55}, T_{60}, T_{2 \mathrm{~h}}$ measurement periods $(p<0.02)$. The IOP in the contralateral eye did not significantly increase throughout the treatment period: the IOP values were from $18.5 \pm 3.3 \mathrm{mmHg}$ to $23.0 \pm 6.3 \mathrm{mmHg}$.

In the rabbits, IOP of the left treated eye increased slightly and remained elevated during all measurement periods but was not statistically significantly $(p>$ $0.05)$. Only 25 minutes after the treatment, there was a significant increase of IOP in the left eye compared to the control eye $16.7 \pm 1.3 \mathrm{mmHg}(p=0.043)$. This also was the maximum IOP increase in the treated eye (Table 2). The IOP in the contralateral eye did not significantly increase throughout the treatment period: the IOP values were from $12.7 \pm 3.0 \mathrm{mmHg}$ to $16.0 \pm$ $2.2 \mathrm{mmHg}(p>0.05)$ (Figs. 2 and 3).

Effects of 1\% cyclopentolate on HPD in cats and rabbits Before treatment, there were no significant differences in the HPD between the right and left eyes in either

Table 2. Effect of $1 \%$ cyclopentolate on IOP (mean values \pm SD) in the feline and rabbit's right and left eye.

\begin{tabular}{lcccccc}
\hline & \multicolumn{2}{c}{ Right eye (untreated eye) IOP mmHg } & \multicolumn{2}{c}{ Left eye (treated eye) IOP mmHg } \\
\cline { 2 - 7 } & $\begin{array}{c}\text { Initial IOP } \\
(\text { mean } \pm \text { SD) }\end{array}$ & $\begin{array}{c}\text { Maximal IOP } \\
\text { (mean } \pm \text { SD) } \\
\text { (time) }\end{array}$ & $\begin{array}{c}\text { \% of IOP } \\
\text { increase }\end{array}$ & $\begin{array}{c}\text { Initial IOP } \\
\text { (mean } \pm \text { SD) }\end{array}$ & $\begin{array}{c}\text { Maximal IOP } \\
\text { (mean } \pm \text { SD), } \\
\text { (time) }\end{array}$ & $\begin{array}{c}\% \text { of IOP } \\
\text { increase }\end{array}$ \\
\hline Cat & $20.0 \pm 2.1$ & $\begin{array}{c}23.0 \pm 6.3 \\
(50 \text { minutes })\end{array}$ & $15 \%$ & $21.1 \pm 4.1$ & $\begin{array}{c}28.1 \pm 5.4 * \\
(50 \text { minutes })\end{array}$ & $33.2 \% * *$ \\
Rabbit & $14.7 \pm 2.8$ & $\begin{array}{c}16.0 \pm 2.2 \\
(10 \text { hours })\end{array}$ & $8.8 \%$ & $14.3 \pm 3.1$ & $\begin{array}{c}16.7 \pm 1.3 \\
(15 \text { minutes })\end{array}$ & $16.7 \%$ \\
\hline
\end{tabular}

$* p<0.05$.

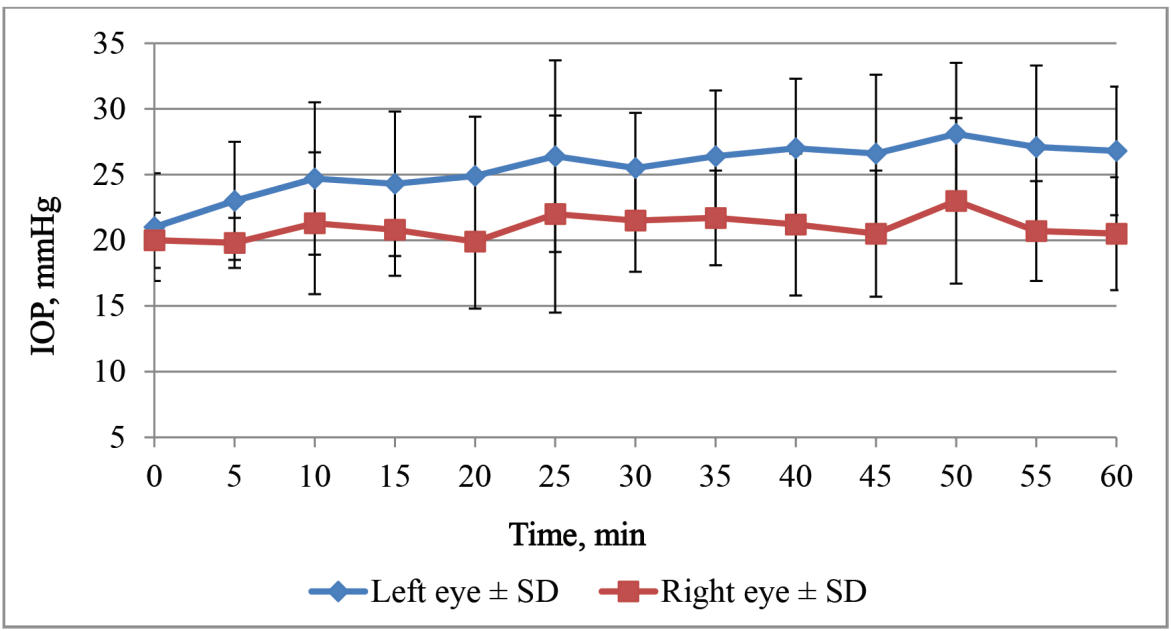

Fig. 1. Effect of unilateral cyclopentolate on the IOP in feline first hour after treatment. 


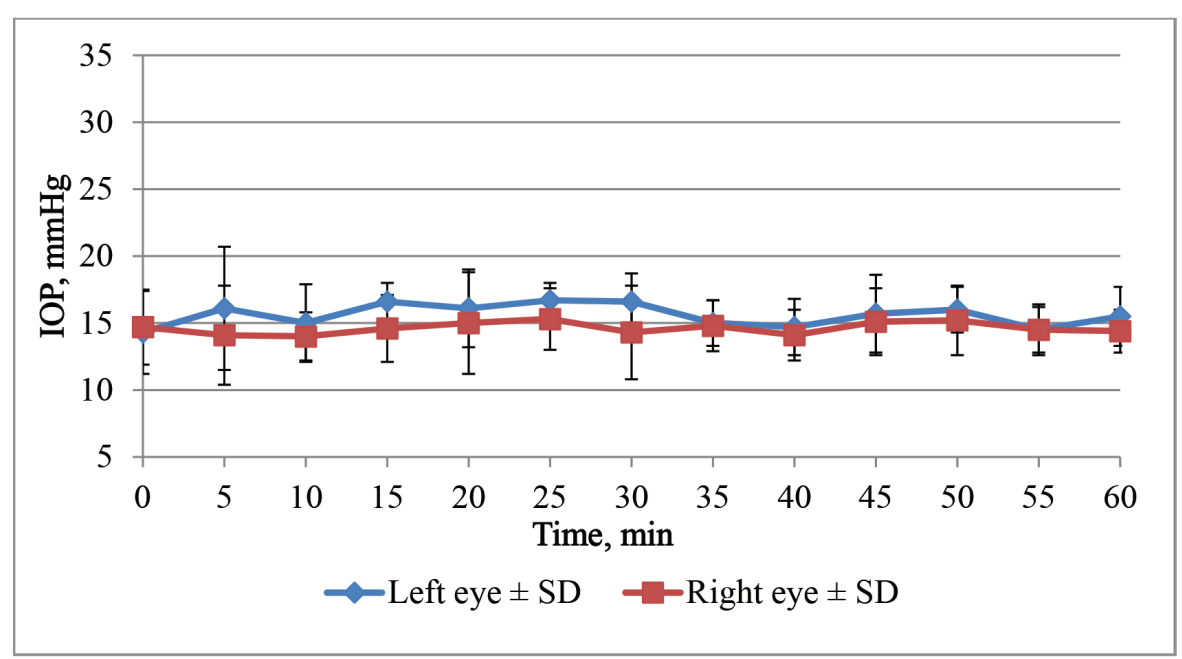

Fig. 2. Effect of unilateral cyclopentolate on the IOP in rabbit first hour after treatment.

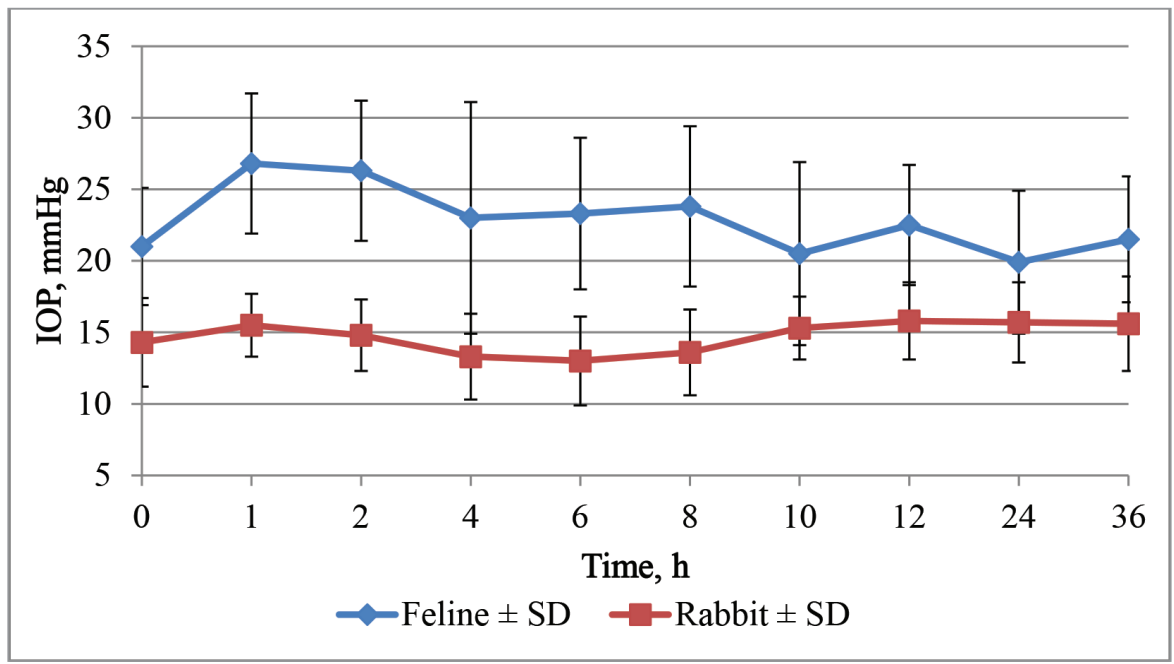

Fig. 3. Effect of unilateral cyclopentolate on the IOP in feline and rabbit in 36 hours.

cats or rabbits $(p>0.05)$. In cats, HPD at $T_{20}$ had increased significantly compared to pre-treatment and control eye (Fig. 4) and continued to increase, reaching a maximum mean value of $14.0 \pm 1.7 \mathrm{~mm}$ at $T_{40}$. The maximum increase in pupil diameter from the $T_{0}$ value until the maximal values was $4.7 \pm 1.2 \mathrm{~mm}(p=0.002)$ (Table 3).

In rabbits, HPD at $T_{10}$ had increased significantly compared to pre-treatment and control eyes and continued to increase, reaching a maximum of $11.1 \pm$ $1.35 \mathrm{~mm}$ at $T_{25}$ (Table 3 ). The increase in pupil diameter from the $T_{0}$ value until the maximum values was $3.1 \pm$ $1.5 \mathrm{~mm}(p=0.004)$. In rabbits HPD returned to pretreatment values at $T_{10 \mathrm{~h}}-T_{12 \mathrm{~h}}$ after treatment $(8.9 \pm 1.9$ and $8.1 \pm 2.1 \mathrm{~mm}$ ) (Fig. 5). Differences in the HPD between the treated and untreated eye were statistically significant from $T_{10}$ to $T_{8 \mathrm{~h}}(p<0.037)$.

In cats, HPD returned to near pre-treatment values only 24-36 hours after treatment $(12.1 \pm 2.6$ and
$11.2 \pm 3.5 \mathrm{~mm}$, respectively) (Fig. 6). Differences in the HPD between the treated and untreated eyes were statistically significant from $T_{20}$ to $T_{24 \mathrm{~h}}(p<0.034)$. The results concerning the pre-treatment and maximum HPD values of HPD in cats and rabbits are shown in Figure 6.

Effects of 1\% cyclopentolate on STT in cats and rabbits The STT results of pre- and post-treatment effects of cyclopentolate in cats and rabbits are shown in Table 4. Before treatment, there were no significant differences in the STT between the right and left eyes of cats and rabbits $(p>0.05)$.

In cats, STT decreased in both eyes significantly at 30 minutes after treatment and remained low throughout the 36 hours period (Fig. 7), showing a maximum decrease in untreated eye to $10.2 \pm 5.5 \mathrm{~mm} /$ minute at 60 minutes and to $11.0 \pm 7.4 \mathrm{~mm} /$ minute in the treated eye 2 hours after treatment (Table 4 ) and reminded at this level throughout till 36 hours after treatment (Fig. 7). 


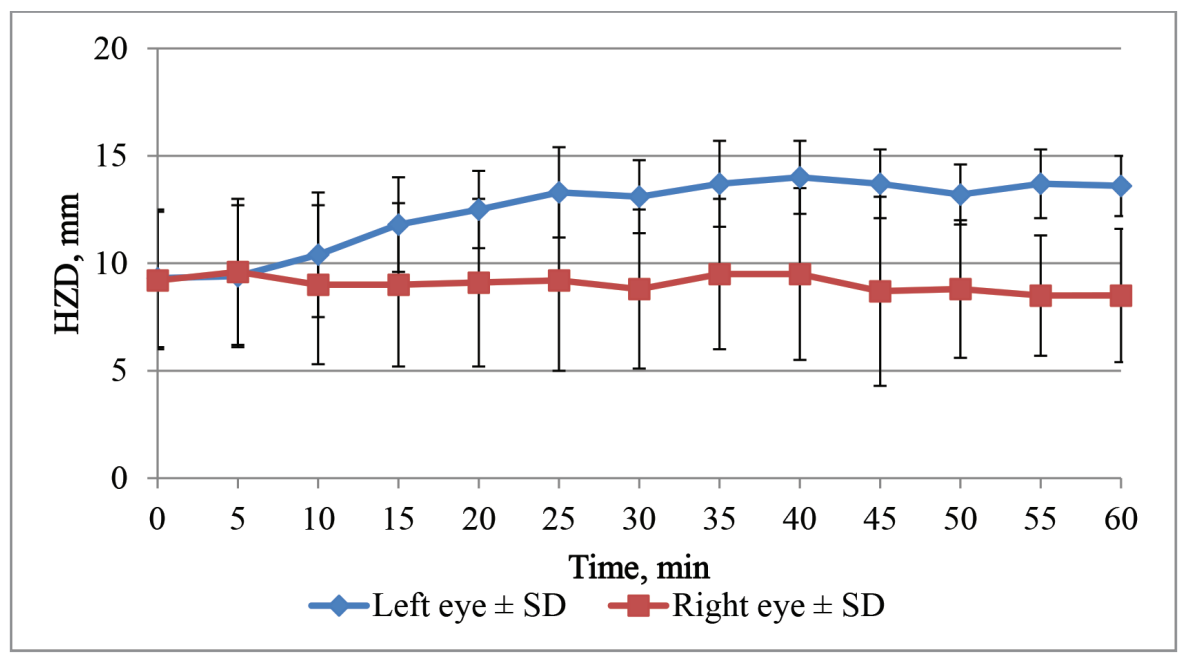

Fig. 4. Effect of unilateral cyclopentolate on the HPD in feline first hour after treatment.

Table 3. Effect of $1 \%$ cyclopentolate on HPD (mean values \pm SD) in the feline and rabbit's right and left eye.

\begin{tabular}{lcccccc}
\hline & \multicolumn{2}{c}{ Right eye (untreated eye) HPD mm } & \multicolumn{2}{c}{ Left eye (treated eye) HPD mm } \\
\cline { 2 - 7 } & $\begin{array}{l}\text { Initial HPD } \\
\text { (mean } \pm \text { SD) }\end{array}$ & $\begin{array}{c}\text { Maximal HPD } \\
\text { (mean } \pm \text { SD) } \\
\text { (time) }\end{array}$ & $\begin{array}{c}\text { \%o of HPD } \\
\text { increase }\end{array}$ & $\begin{array}{c}\text { Initial HPD } \\
\text { (mean } \pm \text { SD) }\end{array}$ & $\begin{array}{c}\text { Maximal HPD } \\
\text { (mean } \pm \text { SD), } \\
\text { (time) }\end{array}$ & $\begin{array}{c}\text { \% of HPD } \\
\text { increase }\end{array}$ \\
\hline Cat & $9.2 \pm 3.2$ & $\begin{array}{c}11.5 \pm 1.9 \\
(12 \text { hours) }\end{array}$ & $25 \%$ & $9.3 \pm 3.2$ & $\begin{array}{c}14.0 \pm 1.7 * \\
(40 \text { minutes })\end{array}$ & $50.5 \%$ \\
Rabbit & $7.7 \pm 2.1$ & $\begin{array}{c}8.4 \pm 2.3 \\
(2 \text { hours })\end{array}$ & $9 \%$ & $8.0 \pm 2.2$ & $\begin{array}{c}11.1 \pm 1.4 \\
(25 \text { minutes })\end{array}$ & $38.8 \%$ \\
\hline
\end{tabular}

$* p<0.05$.

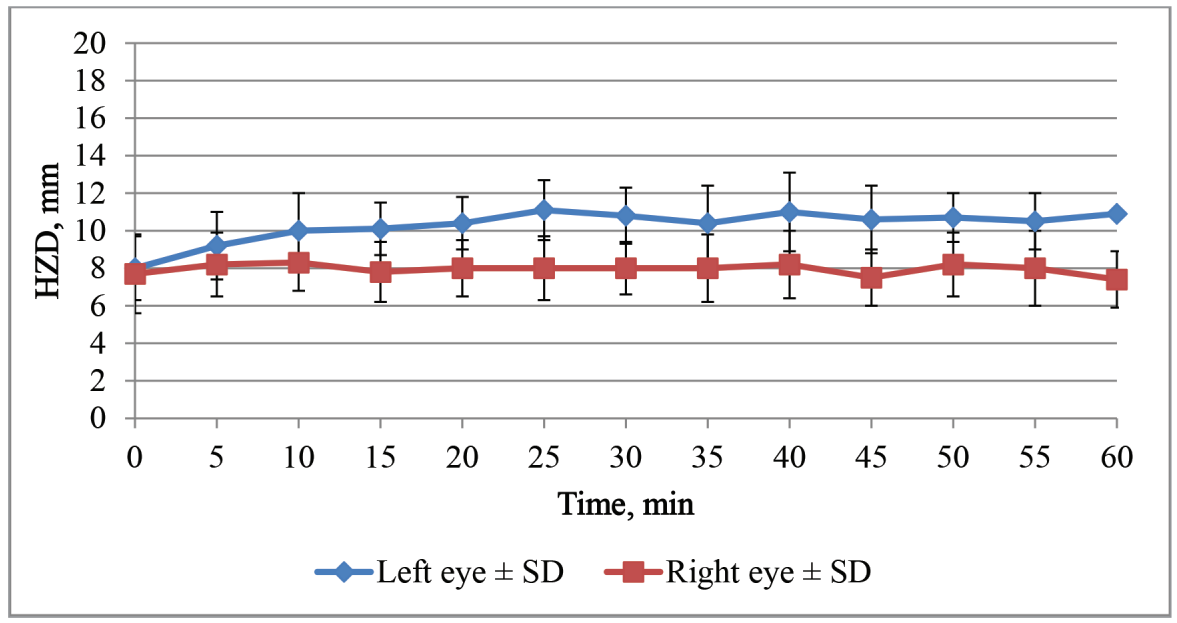

Fig. 5. Effect of unilateral cyclopentolate on the HPD in rabbit first hour after treatment.

In rabbits, STT decreased in the treated eye significantly to the maximum level 30 minutes after cyclopentolate for a $3.7 \pm 2.8 \mathrm{~mm}(p=0.011)$, showing the maximal decrease (Table 4). All following STT measurements returned to normal pre-treatment levels. In the non-treated eye maximal, but non-significant STT decrease was noticed 6 hours after treatment $(p>0.05)$. There were no significant changes between pre-treatment values of treated eye and the control group values $(p>0.05)$ (Fig. 7).

\section{Discussion}

The present study reports on the effects of $1 \%$ cyclopentolate hydrochloride on IOP, HPD, and tear production in healthy cats and healthy rabbits during the 


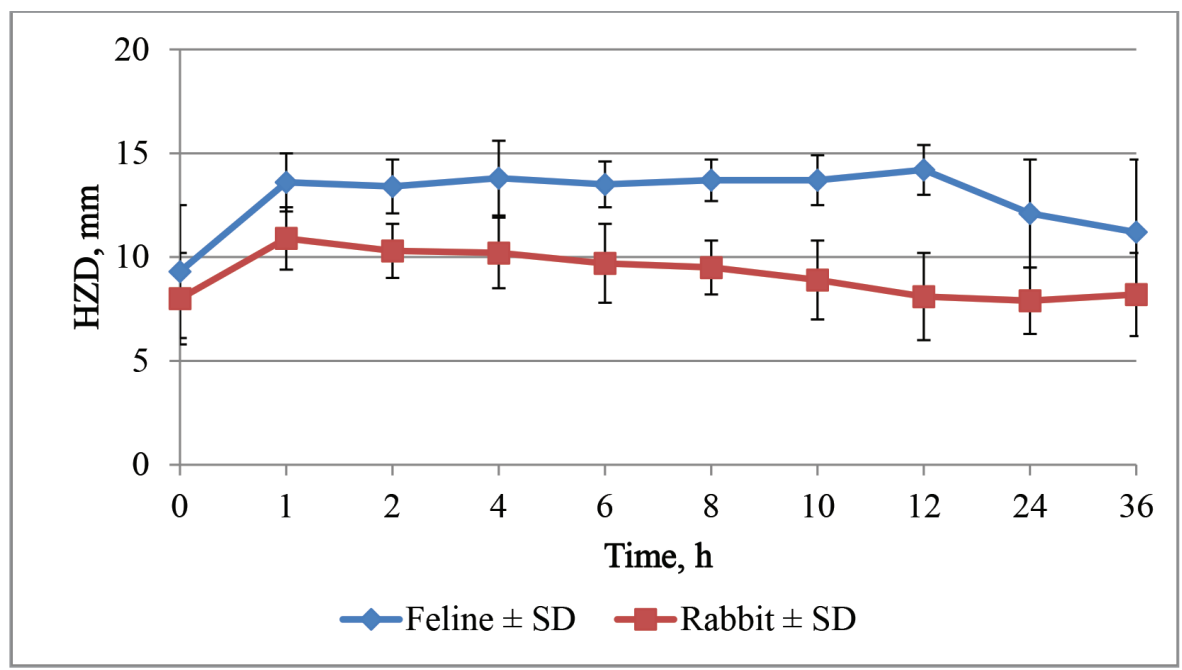

Fig. 6. Effect of unilateral cyclopentolate on the HPD in feline and rabbit in 36 hours.

Table 4. Effect of $1 \%$ cyclopentolate on STT (mean values \pm SD) in the feline and rabbit's right and left eye.

\begin{tabular}{lcccc}
\hline & \multicolumn{2}{c}{ Right eye (untreated eye) STT mm/minute } & \multicolumn{2}{c}{ Left eye (treated eye) STT mm/minute } \\
\cline { 2 - 5 } & $\begin{array}{c}\text { Initial HPD } \\
\text { (mean } \pm \text { SD) }\end{array}$ & $\begin{array}{c}\text { Maximal HPD } \\
\text { (decrease) (mean } \pm \text { SD), } \\
\text { (time) }\end{array}$ & $\begin{array}{c}\text { Initial HPD } \\
\text { (mean } \pm \text { SD) }\end{array}$ & $\begin{array}{c}\text { Maximal HPD } \\
\text { (decrease) (mean } \pm \text { SD), } \\
\text { (time) }\end{array}$ \\
\hline Cat & $15.8 \pm 6.1$ & $10.2 \pm 5.5(60$ minutes) & $17.3 \pm 5.6$ & $11.0 \pm 7.4 *(2$ hours $)$ \\
Rabbit & $9.6 \pm 3.4$ & $6.1 \pm 3.4(6$ hours $)$ & $10.4 \pm 4.3$ & $6.7 \pm 2.2 *(30$ minutes $)$ \\
\hline
\end{tabular}

"p $<0.05$.

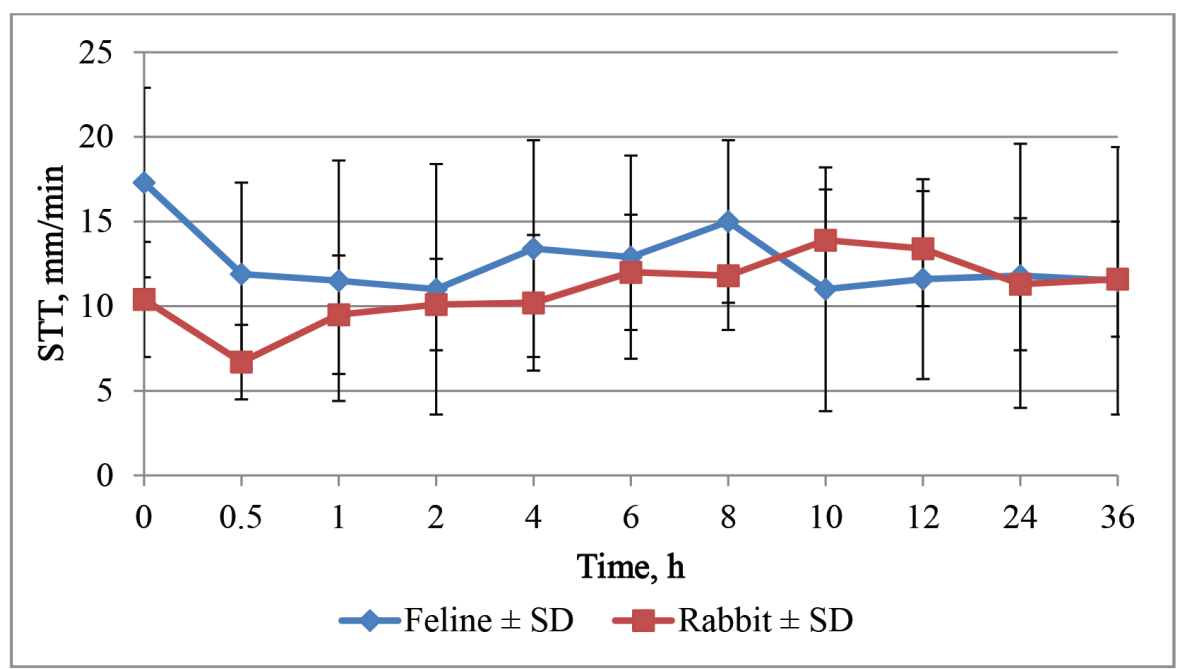

Fig. 7. Effect of unilateral cyclopentolate on the STT in feline and rabbit in 36 hours.

first hour and continuing until 36 hour after treatment. To the author's knowledge, this is a first report on the effects of $1 \%$ cyclopentolate on IOP, HPD, and STT in rabbits and on STT in cats. Most importantly, this study evaluates these effects during the first hour after treatment which is clinically the most relevant and critical time.

In this research, the IOP, HPD, and STT were measured before the topical administration of the cyclopentolate eye drop in all cats and rabbits. The IOP in cats was $20.0 \pm 2.1 \mathrm{mmHg}$ in the right eye and $21.1 \pm 4.1 \mathrm{mmHg}$ in the left eye, which is similar to previously reported values-20.74 mmHg (Rusanen et al., 2010) and range of IOP in Stadtbäumer research (16-21 mmHg) (Stadtbäumer et al., 2006). In mixed breed rabbits, the normal IOP average was $14.7 \pm 2.8 \mathrm{mmHg}$ in the right eye and $14.3 \pm 3.1 \mathrm{mmHg}$ in the left eye. Previously 
reported values in adult New Zealand White rabbits were lower, $9.51 \pm 2.62 \mathrm{mmHg}$ (Pereira et al., 2011). In this study, the average STT before drug administration in all cats included in this study was $15.8 \pm 6.1 \mathrm{~mm} /$ minute in the right eye and $17.3 \pm 5.6 \mathrm{~mm} / \mathrm{minute}$ in the left eye, which is similar to previously reported values - 20.80 $\pm 2.25 \mathrm{~mm} /$ minute (in a range of 14 $25 \mathrm{~mm} / \mathrm{minute}$ ) (Aftab et al., 2018). In this study of mixed-breed rabbits, the normal average was STT 9.6 $\pm 4.3 \mathrm{~mm} /$ minute in the right eye and $10.4 \pm 3.4 \mathrm{~mm} /$ minute in the left eye. Previously reported values in adult English Angora were lower, $5.4 \pm 1.6 \mathrm{mmHg}$ and $4.6 \pm 1.2 \mathrm{mmHg}$ in Dutch rabbits, respectively (Rajaei et al., 2016).

Mydriatic drugs can cause mechanical obstruction of the iridocorneal angle due to pupillary dilatation or increase the resistance to aqueous outflow through the relaxation of the ciliary muscle (Harris, 1968; Valle, 1974; Velasco et al., 1998); therefore an increase of IOP during use of mydriatics is expected. In this research, a statistically significant increase in IOP was observed at $T_{20}$ and continued to increase to a maximum at $T_{50}$ which was greater than the published normal values in cats (Gelatt et al., 2013). This IOP increase occurred until 2 hours after treatment but at 4 hours after treatment IOP returned to $T_{0}$ values. Stadtbäumer et al. (2006) has shown that $1 \%$ cyclopentolate the same as $1 \%$ atropine and $0.5 \%$ tropicamide caused a significant IOP increase in cats 2 hours after cyclopentolate, 1.5 hours after tropicamide, and even 16 hours post atropine treatment (Stadtbäumer et al., 2006). Stadtbäumer et al. (2006) showed a significant increase of IOP at 1, 1.5, and 2 hours after cyclopentolate treatment; however, no measurements were made during the first hour post-treatment. This study discovered maximum IOP occurred was reached during the first hour after treatment. In rabbits, at the same time we noticed a slight increase of IOP, which showed a significant increase, but clinically not important increase only 25 and 30 minutes after treatment. In author's knowledge, there are no similar data on rabbits, but in the research with Beagles no significant effect on IOP was found at any time point after treatment, showing significant species differences (Costa et al., 2016).

As we know, the onset and duration of mydriatics differ among species, the drug used and its concentration, also in human's pigmentation level of irides (Rubin and Wolfes, 1962; Hug and Olitsky, 2007). About one percentage cyclopentolate in cats reached maximum HPD at $T_{40}$ showing more faster increase of HPD than in Stadtbäumer's work where the maximum of HPD was reached 2 hours after treatment. In our research, maximal IOP values followed 10 minutes after maximal HPD and pupil dilation lasted much longer than IOP increase, arguing against mechanical obstruction of iridocorneal angle as an only mechanism. Also, parasimpatolitics by causing relaxation of the ciliary muscle can reduce ciliary muscle tone and decrease aqueous outflow (Harris, 1968; Velasco et al., 1998). HPD almost reached pre-treatment values 24-36 hours after treatment compared to previous research only after 56 hours (Stadtbäumer et al., 2006), showing long-lasting cyclopentolate effect on HPD in cats. In Beagles, where mydriasis was observed in 30 minutes after treatment and maximum reached 12 hours after treatment, lasted longer than in our research -72 hours (Costa et al., 2016). In goats, maximal mydriasis was observed 1 hour after treatment; duration was even 12 hours, showing good but late-onset mydriasis (Whelan et al., 2011). In rabbits, we found HPD maximal values much earlier, 25 minutes after treatment, at the same time, when maximal IOP increase. Pre-treatment values were obtained 10-12 hours after treatment, which in our mind gives faster mydriasis and shorter duration than in cats, dogs, and goats.

In the author's knowledge, these are the novel data on $1 \%$ cyclopentolate effects on IOP and HPD in rabbits. These results show that cyclopentolate do not influence IOP in rabbits as much as cats, similarly like in dogs, where $1 \%$ cyclopentolate had no effect of IOP in Beagles (Costa et al., 2016), but we need to mention that mydriasis was not enough complete and in author's knowledge to provide a full fundus examination.

Cyclopentolate has similar pharmacokinetics and pharmacodynamics as atropine, and our results possibly show that it has less effect on IOP as atropine in rabbits, but comparing research should be done. There is one report on the effects of cyclopentolate and atropine in rabbits but after multiple everyday treatment; therefore, it is difficult to compare because of different protocols and measurement methods (Sadeghi-Hashjin and Manokzadeh, 2008).

Comparing to cyclopentolate effect in humans, it is showed that maximal mydriasis was observed 10 minutes after treatment (Manny et al., 1993) and 45 minutes (Farhood, 2012). Mood et al. (2019) showed that in horses maximal HPD was obtained only 12 hours after application.

Based on data published previously that there is luck of effect on IOP and HPH in the contralateral non-treated eye, the left eye was used as a control (Stadtbäumer et al., 2006; Gomes et al., 2011). Also, in our research, no statistically significant changes were seen in the control eye, compared to initial value throughout the all measurement period; the authors assumed that there is no significant systemic absorption and therefore no effect on the IOP and HPD in the contralateral eye.

The effects of mydriatics, mainly atropine on tear production are a concern in small animal and human practice. In dogs and cats, topical 1\% atropine has a good mydriatic, cycloplegic but also tear reduction effect (Arnett et al., 1984; Hollingsworth et al., 1992). Contrary $1 \%$ cyclopentolate did not decrease STT in dogs (Costa et al., 2016). In cats and rabbits, we found significant STT decrease 30 minutes after treatment in cats, and decreased STT levels were noticed all 
monitored period- till 36 hours after treatment. Also, in rabbits, STT decreased significantly in the treated eye 30 minutes after cyclopentolate treatment but comparing to cats immediately went back in pre-treatment level. We need to admit that significant STT decrease was reported in both eyes in cats and less pronounced in rabbits that possibly can be more connected to the stress factor and handling stress or other daily rhythm factors more than cyclopentolate (Sebbag et al., 2015). Similar report on tropicamide topical use in cats and dogs showed no effect in dogs but a single dose of tropicamide in one eye caused significant STT reduction in both eyes in cats (Margadant et al., 2003).

We would probably also exclude the systemic effect of cyclopentolate concerning STT decrease in both eyes because in IOP and HPD, there were no changes in the right eye. Our research, generally agrees with Costa et al. (2016) and Mood et al. (2019) results that showed no effects of cyclopentolate on STT in dogs and horses.

In conclusion, the study reported here showed that $1 \%$ cyclopentolate in cats caused mydriasis from 20 to 40 minutes after treatment, significantly increasing IOP at the same time, pupil diameter reached pre-treatment values only 24-36 hours after treatment. In rabbit's mydriasis accrued faster, 10-25 minutes after treatment without significant IOP increase. Mydriasis lasted 10-12 hours. All cats and rabbits were monitored 36 hours. Significant STT decrease was recorded in cats, but more likely were connected to stress factors. This drug could be considered a therapeutical alternative in rabbit more than in cats when the use of cycloplegic drugs is needed.

\section{Conflict of interest}

None of the authors has any financial or personal relationships that could inappropriately influence or bias the content of this paper.

\section{References}

Aftab, G., Rajaei, S,M. and Faghihi, H. 2018. Comparison of the Schirmer tear test I values after placement in ventral and dorsal conjunctival fornixes in healthy cats. J. Feline Med. Surg. 20(12), 1169-1172.

Arnett, B.D., Brightman, A.H. and Musselman, E.E. 1984. Effect of atropine sulfate on tear production in the cat when used with ketamine hydrochloride and acetylpromazine maleate. J. Am. Vet. Med. Assoc. 185, 214-215.

Costa, D., Leiva, M., Coyo, N., Laguna, F., Ríos, J. and Peña Gimenez, M.T. 2016. Effect of topical 1\% cyclopentolate hydrochloride on tear production, pupil size, and intraocular pressure in healthy Beagles. Vet. Ophthalmol. 19(6), 449-453.

Farhood, Q. 2012. Cycloplegic refraction in children with cyclopentolate versus atropine. Clin. Exp. Ophthalmol. 3(7), 239.
Gelatt, K.N., Gilger, B.C. and Kern, T.J. 2013. Veterinary Ophthalmology, 5th ed. Hoboken, NJ: Wiley-Blackwell.

Gelatt, K.N., Gum, G.G., Barrie, K.P. and Williams, L.W. 1981. Diurnal variations in intraocular pressure in normotensive and glaucomatous Beagles. Glaucoma 3, 121-124.

Giannetto, C., Piccione, G. and Giudice, E. 2009. Daytime profile of the intraocular pressure and tear production in normal dog. Vet. Ophthalmol. 12(5), 302-305.

Gomes, F.E., Bentley, E., Lin, T.L. and McLella, G.L. 2011. Effects of unilateral topical administration of $0,5 \%$ tropicamide on anterior segment morphology and intraocular pressure in normal cats and cats with primary congenital glaucoma. Vet. Ophthalmol. 14(Suppl 1), 75-83.

Harris, L.S. 1968. Cycloplegia- induced intraocular pressure elevations. Arch. Ophthalmol. 79, 242246.

Harris, L.S. and Galin, M.A. 1969. Cycloplegic provocative testing. Arch. Ophthalmol. 81(3), 356358.

Hollingsworth, S.R., Canton, D.D., Buyukmihci, N.C. and Farver, T.B. 1992. Effect of topical administrated atropine on tear production in dogs. J. Am. Vet. Med. Assoc. 200, 1481-1484.

Hug, T. and Olitsky, S. 2007. Dilation efficacy: is 1\% cyclopentolate enough? Optometry 78(3), 119-121.

Manny, R.E., Fern, K.D., Zervas, H.J., Cline, G.E., Scott, S.K., White, J.M. and Pass, A.F. 1993. 1\% Cyclopentolate hydrochloride: another look at the time course of cycloplegia using an objective measure of the accommodative response. Optom. Vis. Sci. 70(8), 651-665.

Margadant, D.L., Kirkby, K., Andrew, S.E. and Gelatt, K.N. 2003. Effect of topical tropicamide on tear production as measured by Schirmer's tear test in normal dogs and cats. Vet. Ophthalmol. 6(4), 315320.

Mood, M.A., Rajaei, S.M., Faghihi, F. and Ghiadi, A. 2019. Effect of topical 1\% cyclopentolate hydrochloride on tear production, intraocular pressure, and pupil size in healthy Turkman horses. J. Equine Vet. Sci. 75, 25-29.

Pauli, A.M., Bentley, E., Diehl, K.A. and Miller, P.E. 2006. Effects of the application of neck pressure by a collar or harness on intraocular pressure in dogs. J. Am. Anim. Hosp. Assoc. 42, 207-211.

Pereira, F.Q., Bercht, B.S., Soares, M.G., da Mota, M.G. and Pigatto, J.A. 2011. Comparison of a rebound and an applanation tonometer for measuring intraocular pressure in normal rabbits. Vet. Ophthalmol. 14(5), 321-326.

Rajaei, S.M., Rafiee, S.M., Ghaffari, M.S., Masouleh, M.N. and Jamshidian, M. 2016. Measurement of tear production in English Angora and Dutch 
rabbits. J. Am. Assoc. Lab. Anim. Sci. 55(2), 221223.

Rubin, L.F. and Wolfes, R.L. 1962. Mydriatics for canine ophthalmoscopy. J. Am. Vet. Med. Assoc. 144, 137-141.

Rusanen, E., Florin, M., Hässig, M. and Spiess, B.M. 2010. Evaluation of a rebound tonometer (Tonovet) in clinically normal cat eyes. Vet. Ophthalmol. 13(1), 31-36.

Sadeghi-Hashjin, G. and Manokzadeh, F. 2008. Effects of selected antimuscarinic agents on the intra-ocular pressure in healthy rabbits. Pharmacol. Toxicol. 3(5), 382-385.

Sebbag, L., Kass, P.H. and Maggs, D.J. 2015. Reference values, intertest correlations, and test-retest repeatability of selected tear film tests in healthy cats. J. Am. Vet. Med. Assoc. 246(4), 426-435.

Smith, C.M. and Reynard, A.M. 1992. Antimuscarinic Drugs. In Textbook of pharmacology. Ed., Melsaae RJ. Philadelphia, PA: W.B. Saunders Company Philadelphia, pp: 108-115.
Stadtbäumer, K., Frommlet, F. and Nell, B. 2006. Effects of mydriatics on intraocular pressure and pupil size in the normal feline eye. Vet. Ophthalmol. 9, 233-237.

Valle, O. 1974. Effect of cyclopentolate on the aqueous dynamics in incipient or suspected open-angle glaucoma. Acta Ophthalmol. 123, 52-60.

Velasco, C.J., Euroa, M.P., Garcia, S.J. and Bermundez, R.F. 1998. Changes in intraocular pressure due to Cycloplegia. CLAO J. 86, 111-114.

Ward, D.A. 1998. Clinical ophthalmic pharmacology and therapeutics. In Veterinary ophthalmology. Eds., Gelatt, K.N., 3rd ed. Philadelphia, PA: Lippincott/Williams \& Wilkins, , pp: 291-354.

Whelan, N.C., Castillio-Alcala, F. and Lizarraga, I. 2011. Efficacy of tropicamide, homatropine, cyclopentolate, atropine and hyoscine as mydriatics in Angora goats. N. Z. Vet. J. 59(6), 328-331. 